\title{
Comparison of the hemodynamic response of dexmedetomidine versus additional intravenous lidocaine with propofol during tracheal intubation: a randomized controlled study
}

Rattaphol Seangrung ${ }^{*}$ Koravee Pasutharnchat, Subundit Injampa, Sirima Kumdang and Rojnarin Komonhirun

\begin{abstract}
Background: Laryngoscopy and tracheal intubation are strong stimuli that cause a reflex increase in blood pressure (BP), heart rate (HR), and serum catecholamine level. These can lead to myocardial infarction or cerebrovascular accidents. The purpose of this study is to compare the efficacy of dexmedetomidine and lidocaine combined with propofol in attenuating the hemodynamic response following laryngoscopy and endotracheal intubation.

Methods: This study was a randomized controlled study and adhered to the CONSORT guidelines. One-hundred and six patients undergoing elective general anesthesia with endotracheal intubation were divided randomly into two groups. Group D received dexmedetomidine $\left(1 \mathrm{~g} \mathrm{~kg}^{-1}\right)$ before induction. Group LP received lidocaine $\left(1.5 \mathrm{mg} \mathrm{kg}^{-1}\right)$ before induction with additional propofol $\left(0.5 \mathrm{mg} \mathrm{kg}^{-1}\right)$ before laryngoscopy. The primary endpoint was hemodynamic including systolic (S) BP, diastolic (D) BP, mean arterial blood pressure (MAP) and HR measured before and after induction and $\leq 10 \mathrm{~min}$ after intubation. Secondary outcome was complications/adverse effects.
\end{abstract}

Results: After induction, the mean SBP, DBP, MAP and HR decreased significantly from baseline in both groups except for mean HR in group LP at 1 min. Differences in mean values of SBP, DBP, and MAP were significantly lower in group $\mathrm{D}$ after intubation at 4-10 min $(P<0.05)$. Group LP had a non-inferior effect in blunting BP at all time points except 1 and 2 min after induction, and 2 min after intubation. The mean difference in HR in group $D$ was significantly lower than that in group LP at all time points $(P<0.001)$. Group $D$ had significantly more episodes of bradycardia $(18.87 \% \mathrm{vs}$. $0 \%, P=0.001)$ and hypotension $(52.83 \%$ vs. $15.09 \%, P<0.001)$ than did group LP.

Conclusion: Lidocaine $\left(1.5 \mathrm{mg} \mathrm{kg}^{-1}\right)$ with additional propofol $\left(0.5 \mathrm{mg} \mathrm{kg}^{-1}\right)$ had a non-inferior effect compared with dexmedetomidine $\left(1 \mathrm{~g} \mathrm{~kg}^{-1}\right)$ in attenuating the hemodynamic response following laryngoscopy and endotracheal intubation, and had fewer adverse effects.

Trial registration: Thai Clinical Trial Registry, (TRTC20190206002). Retrospectively registered 4 February 2019.

Keywords: Dexmedetomidine, Lidocaine, Propofol, Hemodynamic response, Intubation

*Correspondence: rattaphol_nu@hotmail.com; rattaphol.ra@gmail.com

Department of Anesthesiology, Faculty of Medicine, Ramathibodi

Hospital, Mahidol University, 270 Rama VI Road, Ratchatewi,

Bangkok 10400, Thailand

(c) The Author(s) 2021. Open Access This article is licensed under a Creative Commons Attribution 4.0 International License, which permits use, sharing, adaptation, distribution and reproduction in any medium or format, as long as you give appropriate credit to the original author(s) and the source, provide a link to the Creative Commons licence, and indicate if changes were made. The images or other third party material in this article are included in the article's Creative Commons licence, unless indicated otherwise in a credit line to the material. If material is not included in the article's Creative Commons licence and your intended use is not permitted by statutory regulation or exceeds the permitted use, you will need to obtain permission directly from the copyright holder. To view a copy of this licence, visit http://creativecommons.org/licenses/by/4.0/. The Creative Commons Public Domain Dedication waiver (http://creativeco mmons.org/publicdomain/zero/1.0/) applies to the data made available in this article, unless otherwise stated in a credit line to the data. 


\section{Background}

General anesthesia requires laryngoscopy and intubation, which can result in increased plasma concentrations of catecholamines [1-3]. An inadequate response to blunt stress can lead to hypertension and dysrhythmias, which can result in myocardial infarction or cerebrovascular accidents $[4,5]$.

Several agents have been employed to attenuate hemodynamic stress responses: dexmedetomidine, lidocaine, fentanyl, esmolol, propofol, or volatile anesthetic agents. Dexmedetomidine is a highly selective agonist of $\alpha-2$ adrenergic receptors. It has a sympatholytic effect through a reduction in the norepinephrine concentration. Dexmedetomidine use can result in a decrease in blood pressure (BP) and heart rate (HR), so suppression of airway and circulatory reflexes during laryngoscopy and intubation is appropriate, $[6,7]$ but bradycardia and hypotension have been reported $[8,9]$.

Lidocaine is an aminoethylamide and prototype of amide-based local anesthetics. Usually, it is administered via the intravenous route at $1.5 \mathrm{mg} \mathrm{kg}^{-1}$ bodyweight for $3 \mathrm{~min}$ before intubation to suppress the hemodynamic response. However, such suppression is not complete and a spike in systolic blood pressure (SBP) at 1-min and 3-min intervals post-intubation has been reported $[10,11]$.

Propofol is another anesthetic drug administered via the intravenous route. An additional dose of propofol $\left(0.5 \mathrm{mg} \mathrm{kg}^{-1}\right)$ before intubation can significantly improve intubation conditions without increasing hypotension risk [12]. However, a study focusing on administration of lidocaine combined with a low dose of propofol to prevent the stress response, and whether it is non-inferior to dexmedetomidine use in facilitating adequate control of hemodynamics during laryngoscopy and intubation, has not been done.

In this study we compare the hemodynamic response and adverse effects/complications of dexmedetomidine versus lidocaine with additional propofol, before during and immediately after intubation.

\section{Methods Design}

The protocol for this prospective, randomized control study was approved (05-60-30) on 17 September 2017 by the Ethics Committee (Chairman: Assistant Professor Dr. Chusak Okascharoen) of the Faculty of Medicine of Ramathibodi Hospital (Mahidol University, Bangkok, Thailand). This trial is registered at Thai Clinical Trial Registry on the 4 February 2019 (http://www.clini caltrials.in.th/TRTC20190206002) and adhered to the CONSORT statement. Written informed consent was obtained from all patients according to the local regulations and to the principles of Helsinki Declaration.

\section{Exclusion criteria}

Patients with hypertension, coronary artery disease, history of atrial fibrillation or other arrhythmias, implanted pacemakers, used of the antiarrhythmic drugs or beta blockers, cerebrovascular disease, a full stomach, or scheduled to have emergency surgery, or who were pregnant were excluded.

\section{Study cohort}

The present study was undertaken in Ramathibodi Hospital from September 2017 to September 2019. One hundred and eleven patients (18-65 years; bodyweight, $40-80 \mathrm{~kg}$; body mass index, $\left.18-24.9 \mathrm{~kg} \mathrm{~m}^{-2}\right)$ with American Society of Anesthesiologists (ASA) physical status III and Mallampati classification grade I-II scheduled for elective surgery under general anesthesia with endotracheal intubation formed the study cohort.

\section{Anesthetic procedure}

All patients who completely signed the inform consent would be accounted for in this study. Patient who was screen failures would be defined as who did not meet all the inclusion criteria and/or met at least on exclusion criteria and the patients who wished for withdraw from the study before randomization. Next,all patients were assessed preoperatively. Preoperative premedication with anxiolytics was not undertaken. In the preoperative suite, parameters at baseline were documented. Patients were hydrated with Ringer's lactate solution approximately $8-10 \mathrm{ml} \mathrm{kg}^{-1}$ within $20 \mathrm{~min}$ and followed by a maintenance infusion. Subsequently, patients were divided randomly by a computer program into two groups. Group D received $1 \mu \mathrm{g} \mathrm{kg}^{-1}$ of dexmedetomidine (Precedex ${ }^{\circledR}$; $\left.100 \mu \mathrm{g} \mathrm{ml}^{-1}\right)$ in $20 \mathrm{ml}$ of physiological (0.9\%) saline over $10 \mathrm{~min}$ before the induction of anesthesia (hereafter termed "induction"). Group LP received $1.5 \mathrm{mg} \mathrm{kg}^{-1}$ of lidocaine (2\% lidocaine hydrochloride injection, preservative-free) in $20 \mathrm{ml}$ of $0.9 \%$ saline over $3 \mathrm{~min}$ before induction by a nurse anesthetist not involved in the study.

Upon arrival in the operating theatre, standard monitoring was recorded and patients underwent supplementation with $100 \%$ oxygen by a face mask at $6 \mathrm{~min}^{-1}$. In both groups, fentanyl $\left(1.0 \mu \mathrm{g} \mathrm{kg}^{-1}\right.$, i.v. $)$ was administered before induction. One minute after fentanyl administration, 1\% propofol (Propofol- ${ }^{\circledR}$ Lipuro; $1.5 \mathrm{mg} \mathrm{kg}^{-1}$ ) was administered to induce hypnosis until loss of consciousness was confirmed. Then, manual control of ventilation with $61 \mathrm{~min}^{-1}$ of $100 \%$ oxygen and $2 \%$ sevoflurane was carried out. Next, rocuronium (Esmeron ${ }^{\circledR}$; 
$\left.0.8-1.0 \mathrm{mg} \mathrm{kg}^{-1}\right)$ was injected. In group LP, an additional dose of propofol $\left(0.5 \mathrm{mg} \mathrm{kg}^{-1}\right)$ was given $60 \mathrm{~s}$ after rocuronium administration. Ninety seconds after rocuronium administration, endotracheal intubation was undertaken by trainee anesthetists (Fig. 1). During the study, BP, HR, and oxygen saturation were monitored every minute. Another nurse not involved in the study recorded SBP, diastolic blood pressure (DBP), mean arterial pressure (MAP), and HR at preinduction, $1 \mathrm{~min}$ after induction, 2 min after induction, in the intubation phase, as well as $1,2,4,6,8$, and $10 \mathrm{~min}$ after intubation. Hypotension was recorded if SBP $<90 \mathrm{mmHg}$ or decreased $>20 \%$ compared with that at baseline. Bradycardia was noted if HR $<50 \mathrm{bpm}$. Rescue medication was given for hypotension (ephedrine, $6 \mathrm{mg}$, i.v.) and bradycardia (atropine, $0.6 \mathrm{mg}$, i.v.). However, to ensure the patient safety, patient allocation could be unmasked in occurrence of adverse events after study drugs administration. Anesthesiologists who involved in the patient care could stop the study drugs or adjust the infusion rate if the patients had the following conditions as severe hypotension, new onset of atrioventricular block, severe sinus bradycardia, or unexpected difficult airway management. These situations were documented in the record forms. For this the reasons led to protocol deviations. All of this patients were included in the intention to-treat analysis.

\section{Statistical analysis}

Values for SBP, DBP, MAP, HR, and other continuous variables are given as the mean $\pm \mathrm{SD}$. Sex, ASA physical status, and other grouping variables are represented by numbers and percentages. A non-inferior margin of $\mathrm{SBP} \geq 5 \mathrm{mmHg}$ (determined from a study by Gulabani and colleagues [6]) in group LP (compared with group D) was used. Tests (Student's $t$, Mann-Whitney, $x^{2}$ ) were used to compare characteristics between groups. Repeated-measures ANOVA was employed to assess changes over time within and between groups for SBP, MAP, DBP, and HR. SPSS 21.0 (IBM, Armonk, NY, USA) was used for data analyses. $P<0.05$ was considered significant.

\section{Calculation of sample size}

In this study, a non-inferior margin of SBP $\geq 5 \mathrm{mmHg}$ at $3 \mathrm{~min}$ of post-intubation (determined from a study by Gulabani and colleagues [6]) was selected as important indicator for the calculation of the sample size. At the levels of $\alpha=0.05$ and $\beta=0.2$, the sample size of each group was calculated to be at least 53 cases. Considering that approximately $5 \%$ of the patients would withdraw from the study.

\section{Results}

A CONSORT flowchart of our study is shown as Fig. 2. Between October 2017 and September 2019, 111 patients met the inclusion criteria and were recruited. Five patients dropped out owing to protocol violations and the anesthetic procedure was cancelled. Thus, 106 patients were evaluated. There were no intergroup differences in demographic characteristics (Table 1). The values of SBP, DBP, MAP, and HR at baseline were not significantly different (Table 2).

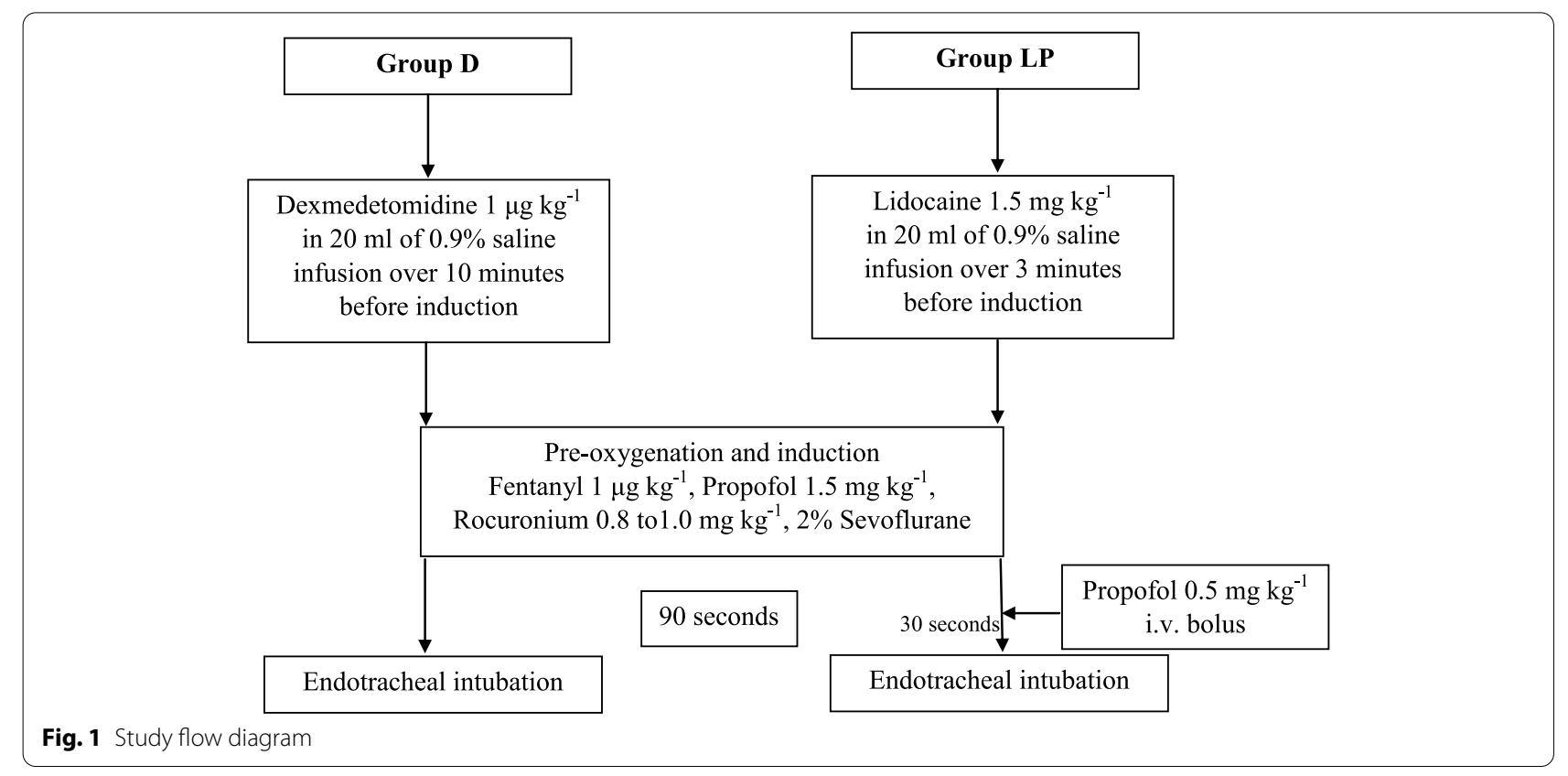




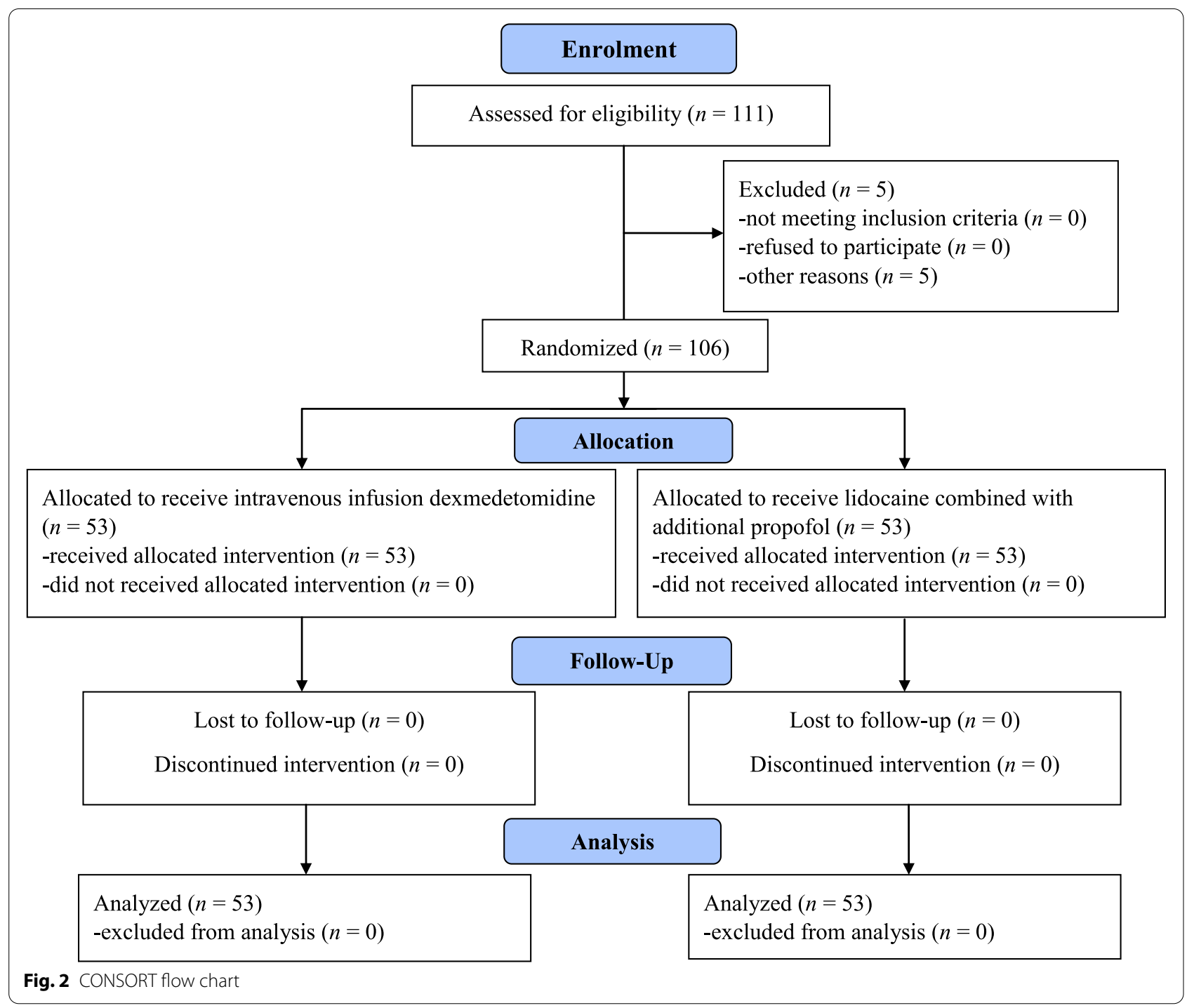

Table 1 Demographic data

\begin{tabular}{llll}
\hline & Group D, $\boldsymbol{n}=\mathbf{5 3}$ & Group LP, $\boldsymbol{n}=\mathbf{5 3}$ & $\boldsymbol{P}$ value \\
\hline Age (years) & $43.49 \pm 13.15$ & $45.04 \pm 11.58$ & 0.522 \\
Male/Female, $n$ & $11 / 42$ & $13 / 40$ & 0.643 \\
BMI (kg m ${ }^{-2}$ ) & $22.49 \pm 2.41$ & $22.35 \pm 2.63$ & 0.775 \\
ASA I/II, $n$ & $26 / 27$ & $22 / 31$ & 0.435 \\
Mallampati score I/II/III, $n$ & $31 / 20 / 2$ & $38 / 15 / 0$ & 0.205 \\
$\begin{array}{l}\text { Time of intubation } \\
\text { (seconds) }\end{array}$ & $26.6 \pm 9.03$ & $30.19 \pm 17.7$ & 0.192 \\
$\begin{array}{l}\text { Attempt of intubation } \\
\text { (times) }\end{array}$ & 1 (constant) & 1 (constant) & - \\
Laryngoscopic view & $47 / 6$ & & \\
1/2, $n$ & & $48 / 5$ & 0.75 \\
\hline
\end{tabular}

Data are presented as mean $\pm S D$ or number count

ASA American Society of Anesthesiologist physical status classification system, $B M I$ Body mass index
SBP, DBP, and MAP in group LP were decreased from baseline values more than those in group $\mathrm{D}$ at $1 \mathrm{~min}$ and 2 min after induction (SBP: -14.73 and -27.01 vs. -13.15 and $-20.83 \mathrm{mmHg}$; DBP: -6.07 and -15.00 vs. -4.47 and $-9.45 \mathrm{mmHg}$ : MAP: -9.64 and -18.66 vs. -7.71 and $-12.20 \mathrm{mmHg}$, respectively) but were not significantly different between groups (Figs. 3 and 4, Table 2). Simultaneously, in group LP, SBP at $2 \mathrm{~min}$ after induction decreased $>20 \%$ from that at baseline $(-27.01 \mathrm{mmHg} ; 20 \%$ of the mean SBP at baseline [130.26 mmHg] was $26.05 \mathrm{mmHg}$ ) but this value was not significantly different when compared with the SBP of group D (Table 2).

In the intubation period, only the SBP in group D was significantly lower than that at baseline $(P<0.05)$. The SBP, DBP, and MAP were not significantly different when compared between groups (Table 2). 
Table 2 Blood pressure $(\mathrm{mmHg})$ and heart rate (bpm) at different time points

\begin{tabular}{|c|c|c|c|c|c|c|c|c|}
\hline & \multicolumn{3}{|l|}{ DEX (53) } & \multicolumn{3}{|l|}{$\mathbf{L P}(53)$} & \multirow{2}{*}{$\begin{array}{l}\text { Mean difference between } \\
\text { groups } \\
\text { (DEX-LP) }(90 \% \text { Cl) }\end{array}$} & \multirow[t]{2}{*}{$P$ value } \\
\hline & Mean $(\mathrm{mmHg})$ & \multicolumn{2}{|l|}{$\begin{array}{l}\text { Mean difference within } \\
\text { group }\end{array}$} & Mean $(\mathrm{mmHg})$ & \multicolumn{2}{|l|}{$\begin{array}{l}\text { Mean difference within } \\
\text { group }\end{array}$} & & \\
\hline \multicolumn{9}{|c|}{ Systolic blood pressure } \\
\hline \multirow[t]{2}{*}{$B L$} & $128.25 \pm 18.36$ & & & $130.26 \pm 15.01$ & & & $-2.019(-7.425-3.388)$ & 0.537 \\
\hline & & From BL & $P$ value $^{\dagger}$ & & From BL & $P$ value $^{\dagger}$ & & \\
\hline BF-IND & $124.83 \pm 17.8$ & -3.415 & 0.060 & $132.28 \pm 14.57$ & 2.019 & 0.192 & $\begin{array}{l}-7.453[-12.697- \\
(-2.208)]\end{array}$ & $0.020^{*}$ \\
\hline AFT-IND 1 & $115.09 \pm 19.61$ & -13.151 & $<0.001^{*}$ & $115.53 \pm 18.88$ & -14.736 & $<0.001^{*}$ & $-0.434(-6.639-5.771)$ & 0.908 \\
\hline AFT-IND 2 & $107.42 \pm 19.05$ & -20.830 & $<0.001^{*}$ & $103.25 \pm 17.85$ & -27.019 & $<0.001^{*}$ & $4.17(-1.781-10.121)$ & 0.248 \\
\hline INT & $121.28 \pm 22.41$ & -6.962 & $0.015^{*}$ & $126.92 \pm 26.33$ & -3.340 & 0.389 & $-5.642(-13.523-2.239)$ & 0.238 \\
\hline AFT-INT 1 & $117.66 \pm 21.36$ & -10.585 & $<0.001^{*}$ & $121.4 \pm 24.56$ & -8.868 & $0.014^{*}$ & $-3.736(-11.155-3.683)$ & 0.405 \\
\hline AFT-INT 2 & $116.15 \pm 44.22$ & -12.094 & 0.073 & $118.62 \pm 20.64$ & -11.642 & $<0.001^{*}$ & $-2.472(-13.597-8.654)$ & 0.713 \\
\hline AFT-INT 4 & $102.47 \pm 16.17$ & -25.774 & $<0.001^{*}$ & $117.3 \pm 21.2$ & -12.962 & $0.001^{*}$ & $\begin{array}{l}-14.83[-20.908- \\
(-8.752)]\end{array}$ & $<0.001^{*}$ \\
\hline AFT-INT 6 & $98.96 \pm 13.97$ & -29.283 & $<0.001^{*}$ & $108.96 \pm 14.47$ & -21.302 & $<0.001^{*}$ & $\begin{array}{l}-10[-14.585- \\
(-5.415)]\end{array}$ & $<0.001^{*}$ \\
\hline AFT-INT 8 & $97.26 \pm 16.56$ & -30.981 & $<0.001^{*}$ & $105.13 \pm 13.45$ & -25.132 & $<0.001^{*}$ & $\begin{array}{l}-7.868[-12.73- \\
(-3.005)]\end{array}$ & $0.008^{*}$ \\
\hline \multirow[t]{2}{*}{ AFT-INT 10} & $96.32 \pm 13.74$ & -31.925 & $<0.001^{*}$ & $105.47 \pm 14.01$ & -24.792 & $<0.001^{*}$ & $\begin{array}{l}-9.151[-13.625- \\
(-4.677)]\end{array}$ & $0.001^{*}$ \\
\hline & & \multicolumn{2}{|c|}{$\begin{array}{l}\text { Note: } \\
\text { BL Mean } 128.25 \text {, so } 20 \% \text { Mean } \cong 25.65\end{array}$} & & \multicolumn{2}{|c|}{$\begin{array}{l}\text { Note: } \\
\text { BL Mean } 130.26 \text {, so } 20 \% \text { Mean } \cong 26.05\end{array}$} & & \\
\hline \multicolumn{9}{|c|}{ Result from repeated measures ANOVA (a within-subjects factor included 11 measurements) show no significant difference of the Between-groups effects ( $P=0.036^{*}$ ) } \\
\hline \multicolumn{9}{|c|}{ Diastolic blood pressure } \\
\hline \multirow[t]{2}{*}{ BL } & $77.7 \pm 12.75$ & & & $79.13 \pm 9.92$ & & & $-1.434(-5.117-2.249)$ & 0.520 \\
\hline & & From BL & $P$ value $^{\dagger}$ & & From BL & $P$ value $^{\dagger}$ & & \\
\hline BF-IND & $75.74 \pm 11.92$ & -1.962 & 0.167 & $80.08 \pm 9.74$ & 0.943 & 0.447 & $-4.34[-7.849-(-0.83)]$ & $0.043^{*}$ \\
\hline AFT-IND 1 & $73.23 \pm 12.6$ & -4.472 & $0.025^{*}$ & $73.06 \pm 14.51$ & -6.075 & $0.004^{*}$ & $0.17(-4.21-4.55)$ & 0.949 \\
\hline AFT-IND 2 & $68.25 \pm 14.42$ & -9.453 & $<0.001^{*}$ & $64.13 \pm 14.58$ & -15.000 & $<0.001^{*}$ & $4.113(-0.562-8.788)$ & 0.147 \\
\hline INT & $78.53 \pm 16.96$ & 0.830 & 0.704 & $83.91 \pm 19.77$ & 4.774 & 0.105 & $-5.377(-11.316-0.561)$ & 0.136 \\
\hline AFT-INT 1 & $77.43 \pm 16.87$ & -0.264 & 0.917 & $79.26 \pm 17.06$ & 0.132 & 0.959 & $-1.83(-7.299-3.638)$ & 0.580 \\
\hline AFT-INT 2 & $71.79 \pm 14.25$ & -5.906 & $0.011^{*}$ & $76.26 \pm 14.72$ & -2.868 & 0.162 & $-4.472(-9.142-0.198)$ & 0.115 \\
\hline AFT-INT 4 & $66.57 \pm 14.1$ & -11.132 & $<0.001^{*}$ & $75.87 \pm 18.44$ & -3.264 & 0.192 & $\begin{array}{l}-9.302[-14.594- \\
(-4.009)]\end{array}$ & $0.004^{*}$ \\
\hline AFT-INT 6 & $62.45 \pm 11.69$ & -15.245 & $<0.001^{*}$ & $68.66 \pm 13.27$ & -10.472 & $<0.001^{*}$ & $\begin{array}{l}-6.208[-10.24- \\
(-2.175)]\end{array}$ & $0.012^{*}$ \\
\hline AFT-INT 8 & $60.74 \pm 13.61$ & -16.962 & $<0.001^{*}$ & $66.47 \pm 13.09$ & -12.660 & $<0.001^{*}$ & $\begin{array}{l}-5.736[-10.039- \\
(-1.432)]\end{array}$ & $0.029^{*}$ \\
\hline AFT-INT 10 & $61.42 \pm 10.16$ & -16.283 & $<0.001^{*}$ & $67.11 \pm 12.2$ & -12.019 & $<0.001^{*}$ & $\begin{array}{l}-5.698[-9.318- \\
(-2.079)]\end{array}$ & $0.010^{*}$ \\
\hline \multicolumn{9}{|c|}{ Result from repeated measures ANOVA (a within-subjects factor included 11 measurements) show no significant difference of the Between-groups effects $\left(P=0.045^{*}\right)$} \\
\hline \multicolumn{9}{|c|}{ Mean arterial pressure } \\
\hline \multirow[t]{2}{*}{ BL $\quad$} & $91.68 \pm 13.93$ & & & $92.85 \pm 10.72$ & & & $-1.17(-5.176-2.836)$ & 0.629 \\
\hline & & From BL & $P$ value $^{\dagger}$ & & From BL & $P$ value $^{\dagger}$ & & \\
\hline BF-IND & $89.6 \pm 12.44$ & -2.075 & 0.139 & $93.25 \pm 10.89$ & 0.396 & 0.745 & $-3.642(-7.41-0.127)$ & 0.112 \\
\hline AFT-IND 1 & $83.96 \pm 12.93$ & -7.717 & $0.001^{*}$ & $83.21 \pm 15.66$ & -9.642 & $<0.001^{*}$ & $0.755(-3.875-5.384)$ & 0.787 \\
\hline AFT-IND 2 & $79.47 \pm 14.26$ & -12.208 & $<0.001^{*}$ & $74.19 \pm 15.5$ & -18.660 & $<0.001^{*}$ & $5.283(0.482-10.084)$ & 0.071 \\
\hline INT & $90.74 \pm 17.31$ & -0.943 & 0.689 & $96.64 \pm 21.36$ & 3.792 & 0.196 & $-5.906(-12.173-0.362)$ & 0.121 \\
\hline AFT-INT 1 & $88.79 \pm 17.27$ & -2.887 & 0.265 & $91.26 \pm 17.98$ & -1.585 & 0.558 & $-2.472(-8.154-3.211)$ & 0.472 \\
\hline AFT-INT 2 & $81.77 \pm 14.63$ & -9.906 & $<0.001^{*}$ & $88 \pm 15.67$ & -4.849 & $0.032^{*}$ & $\begin{array}{l}-6.226[-11.113- \\
(-1.34)]\end{array}$ & $0.037^{*}$ \\
\hline AFT-INT 4 & $75.55 \pm 13.95$ & -16.132 & $<0.001^{*}$ & $87.02 \pm 18.49$ & -5.830 & $0.031^{*}$ & $\begin{array}{l}-11.472[-16.753- \\
(-6.191)]\end{array}$ & $<0.001^{*}$ \\
\hline AFT-INT 6 & $72.21 \pm 11.71$ & -19.472 & $<0.001^{*}$ & $79.45 \pm 13.36$ & -13.396 & $<0.001^{*}$ & $\begin{array}{l}-7.245[-11.296- \\
(-3.195)]\end{array}$ & $0.004^{*}$ \\
\hline AFT-INT 8 & $71.87 \pm 14.53$ & -19.811 & $<0.001^{*}$ & $77.21 \pm 13.48$ & -15.642 & $<0.001^{*}$ & $\begin{array}{l}-5.34[-9.858- \\
(-0.821)]\end{array}$ & 0.053 \\
\hline
\end{tabular}


Table 2 (continued)

\begin{tabular}{|c|c|c|c|c|c|c|c|c|}
\hline AFT-INT 10 & $71.45 \pm 10.46$ & -20.226 & $<0.001^{*}$ & $77.79 \pm 12.27$ & -15.057 & $<0.001^{*}$ & $\begin{array}{l}-6.34[-10.015- \\
(-2.664)]\end{array}$ & $0.005^{*}$ \\
\hline \multicolumn{9}{|c|}{ Result from repeated measures ANOVA (a within-subjects factor included 11 measurements) show no significant difference of the Between-groups effects $\left(P=0.035^{*}\right)$} \\
\hline & \multicolumn{3}{|c|}{ DEX (53) } & \multicolumn{3}{|c|}{$\mathbf{L P}(53)$} & \multirow{2}{*}{$\begin{array}{l}\text { Mean difference between } \\
\text { groups } \\
\text { (DEX-LP) }(90 \% \text { Cl) }\end{array}$} & \multirow[t]{2}{*}{$P$ value } \\
\hline & $\begin{array}{l}\text { Mean } \\
(\mathrm{bpm})\end{array}$ & $\begin{array}{l}\text { Mean difference } \\
\text { within group }\end{array}$ & & $\begin{array}{l}\text { Mean } \\
(\mathrm{bpm})\end{array}$ & $\begin{array}{l}\text { Mean difference } \\
\text { within group }\end{array}$ & & & \\
\hline \multicolumn{9}{|l|}{ Heart rate } \\
\hline \multirow[t]{2}{*}{$B L$} & $74.42 \pm 14.03$ & & & $78.7 \pm 13.55$ & & & $-4.283(-8.729-0.163)$ & 0.113 \\
\hline & & From BL & $P$ value $^{+}$ & & From BL & $P$ value $^{\dagger}$ & & \\
\hline BF-IND & $66.43 \pm 15.22$ & -7.981 & $<0.001^{*}$ & $79.47 \pm 13.45$ & 0.774 & 0.589 & $\begin{array}{l}-13.038[-17.668- \\
(-8.407)]\end{array}$ & $<0.001^{*}$ \\
\hline AFT-IND 1 & $61.51 \pm 13.69$ & -12.906 & $<0.001^{*}$ & $76.02 \pm 13.36$ & -2.679 & 0.137 & $\begin{array}{l}-14.509[-18.87- \\
(-10.149)]\end{array}$ & $<0.001^{*}$ \\
\hline AFT-IND 2 & $60.81 \pm 13.74$ & -13.604 & $<0.001^{*}$ & $73.28 \pm 11.73$ & -5.415 & $0.002^{*}$ & $\begin{array}{l}-12.472[-16.59- \\
(-8.353)]\end{array}$ & $<0.001^{*}$ \\
\hline INT & $70.53 \pm 13.51$ & -3.887 & 0.057 & $84.64 \pm 16.12$ & 5.943 & $0.009^{*}$ & $\begin{array}{l}-14.113[-18.909- \\
(-9.318)]\end{array}$ & $<0.001^{*}$ \\
\hline AFT-INT 1 & $72.92 \pm 12.88$ & -1.491 & 0.448 & $82.62 \pm 14.34$ & 3.925 & $0.046^{*}$ & $\begin{array}{l}-9.698[-14.093- \\
(-5.303)]\end{array}$ & $<0.001^{*}$ \\
\hline AFT-INT 2 & $71.11 \pm 11.07$ & -3.302 & 0.065 & $82.4 \pm 13.83$ & 3.698 & 0.065 & $\begin{array}{l}-11.283[-15.322- \\
(-7.244)]\end{array}$ & $<0.001^{*}$ \\
\hline AFT-INT 4 & $69.58 \pm 10.82$ & -4.830 & $0.005^{*}$ & $80.43 \pm 13.03$ & 1.736 & 0.373 & $\begin{array}{l}-10.849[-14.711- \\
(-6.987)]\end{array}$ & $<0.001^{*}$ \\
\hline AFT-INT 6 & $67.11 \pm 10.54$ & -7.302 & $<0.001^{*}$ & $78.58 \pm 13.03$ & -0.113 & 0.956 & $\begin{array}{l}-11.472[-15.293- \\
(-7.651)]\end{array}$ & $<0.001^{*}$ \\
\hline AFT-INT 8 & $66.49 \pm 9.27$ & -7.925 & $<0.001^{*}$ & $76.57 \pm 12.64$ & -2.132 & 0.304 & $\begin{array}{l}-10.075[-13.653- \\
(-6.498)]\end{array}$ & $<0.001^{*}$ \\
\hline AFT-INT 10 & $65.13 \pm 9.86$ & -9.283 & $<0.001^{*}$ & $74.11 \pm 12.37$ & -4.585 & $0.022^{*}$ & $\begin{array}{l}-8.981[-12.587- \\
(-5.376)]\end{array}$ & $<0.001^{*}$ \\
\hline
\end{tabular}

Result from repeated measures ANOVA (a within-subjects factor included 11 measurements) show no significant difference of the Between-groups effects $\left(P<0.001^{*}\right.$ )

\section{Data are mean $\pm S D$}

$B L$ Baseline, BF-IND Before induction, AFT-IND $n$ After induction at $n$ min, INT Intubation, AFT-INT $n$ After intubation at $n$ min

${ }^{*} P$ - value $<0.05$ (two-sided tests)

† compared with "Baseline" value within individual groups using paired t-tests

‡ compared across groups at each time point using independent t-tests

For group D, the mean SBP, DBP, and MAP decreased significantly from baseline at $4-10 \mathrm{~min}$ after intubation $(P<0.001)$, and the mean differences were significantly lower than those in group LP. Meanwhile, the SBP decreased $>20 \%$ from baseline in group D at $4-10 \mathrm{~min}$ after intubation (20\% of the mean SBP at baseline [128.25 mmHg] was $25.65 \mathrm{mmHg}$ ) (Table 2).

A forest plot showing the difference in SBP between groups is shown as Fig. 5. A non-inferior margin of SBP $\geq 5 \mathrm{mmHg}$ (determined from a study by Gulabani and colleagues $^{6}$ ) in group LP (compared with group D) was used in our study. Group LP had a non-inferior effect in blunting BP at all time points except $1 \mathrm{~min}$ and $2 \mathrm{~min}$ after induction, and 2 min after intubation.

The mean difference in HR in group D was significantly lower than that in group LP in each period from preinduction until $10 \mathrm{~min}$ after intubation $(P<0.001)$ (Fig. 6,
Table 2). Nevertheless, in group LP, the HR decreased significantly from baseline to $2 \mathrm{~min}$ after induction (73.28 $\pm 11.73 \mathrm{bpm}$; mean difference, $-5.41 ; P<0.05)$ and increased significantly from baseline to the intubation phase $(84.64 \pm 16.12 \mathrm{bpm}$; mean difference, $5.94 ; P<0.05)$ and $1 \mathrm{~min}$ after intubation $(82.62 \pm 14.34 \mathrm{bpm}$; mean difference, 3.92, $P<0.05$ ) (Table 2).

Bradycardia and hypotension occurred in group D significantly more often than in group LP. The prevalence of bradycardia in group D was $18.87 \%$, whereas bradycardia did not occur in group LP. The prevalence of hypotension in group D was $52.83 \%$, whereas it was $15.09 \%$ in group LP (Table 3). 


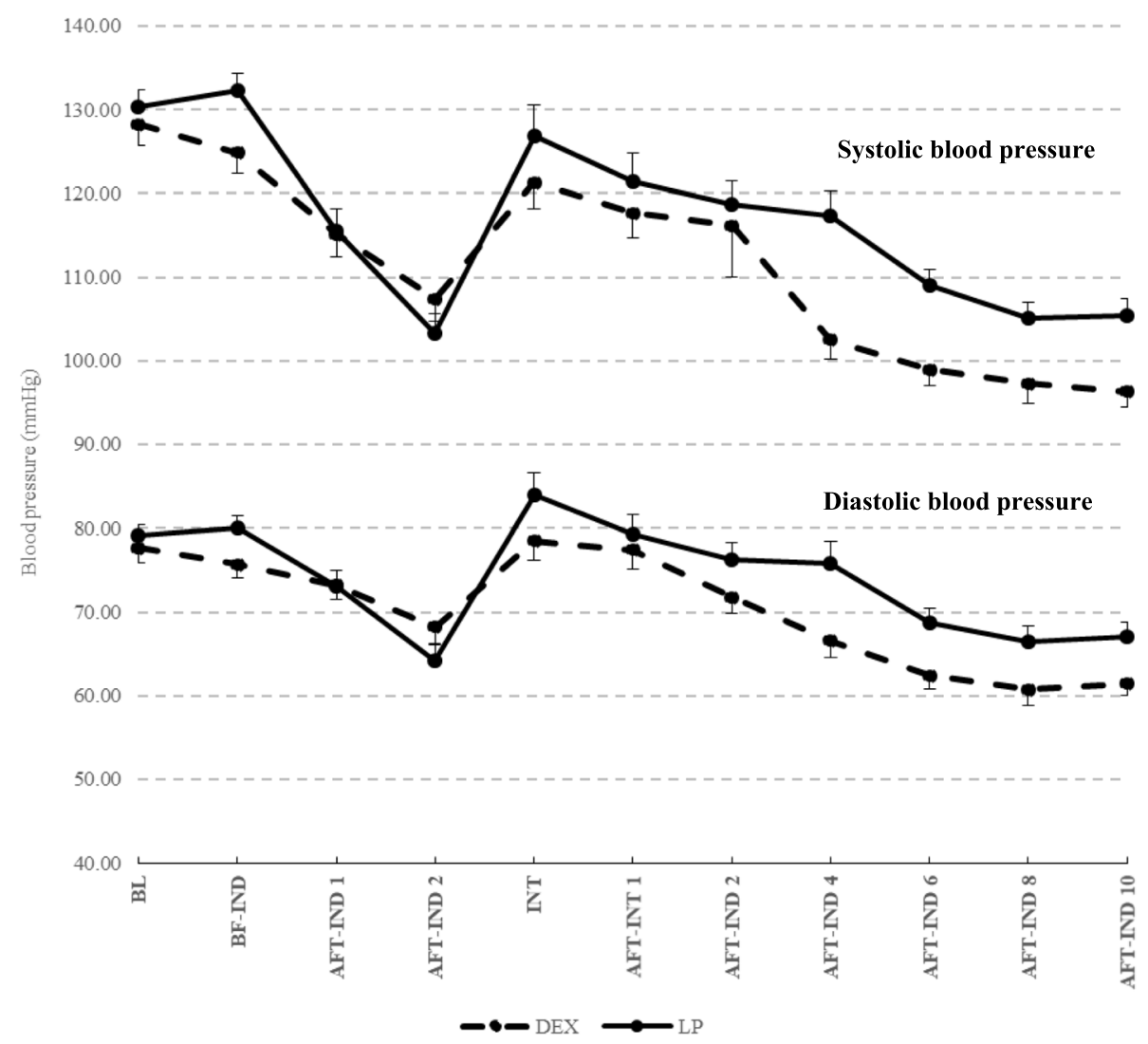

Fig. 3 Mean of Systolic and Diastolic Arterial Blood Pressure for each time point (Dash line, DEX; Solid line, LP)

\section{Discussion}

Laryngoscopy and endotracheal intubation are strong stimuli. They can cause a sympathomimetic response that manifests as hypertension and dysrhythmias that can lead to myocardial infarction and cerebrovascular accidents [4]. Reddy and colleagues [8] and Yildiz and coworkers [9] found that dexmedetomidine could blunt the sympathomimetic response to laryngoscopy and endotracheal intubation, but also resulted in hypotension and bradycardia. In the present study, dexmedetomidine had similar effects to those recorded in the studies by Reddy and colleagues [8] and Yildiz and coworkers [9]. That is, SBP and MAP decreased after induction, and decreased significantly $4-10 \mathrm{~min}$ after intubation. SBP decreased $>20 \%$ from that recorded at baseline after intubation, which denoted hypotension. The HR decreased significantly during induction as well as $4-10 \mathrm{~min}$ after intubation when compared with the HR at baseline. In the intubation period, only SBP changed significantly from baseline: it decreased $\leq 20 \%$ from that at baseline.
From the previous study, Dashti and colleagues [13] compared hemodynamic alterations following tracheal intubation with the GlideScope ${ }^{\circledR}$ video-laryngoscope (GVL) and the Macintosh direct laryngoscope (MDL). It has been shown to increase of blood pressure and heart rate during oropharyngeal, laryngeal and tracheal stimulation. Then, both blood pressure and heart rate would return to pre-intubation values at 3 and $4 \mathrm{~min}$ after intubation, respectively. Therefore, these changes were transient and returned to the baseline levels within 5 min after intubation because of discontinuing airway stimulation. Our study demonstrated that dexmedetomidine elicited extreme alterations in hemodynamics 4-10 min after intubation. It was probably due to a result of pharmacodynamic interactions of dexmedetomidine with anesthetics, sedatives, and opioids might lead to the decline of blood pressure and heart rate after $4 \mathrm{~min}$. Thus, co-administration of dexmedetomidine with propofol or opioids can lead to hemodynamic instability. However, Cabrini and colleagues [14] published the recent systematic review of randomized controlled trials 


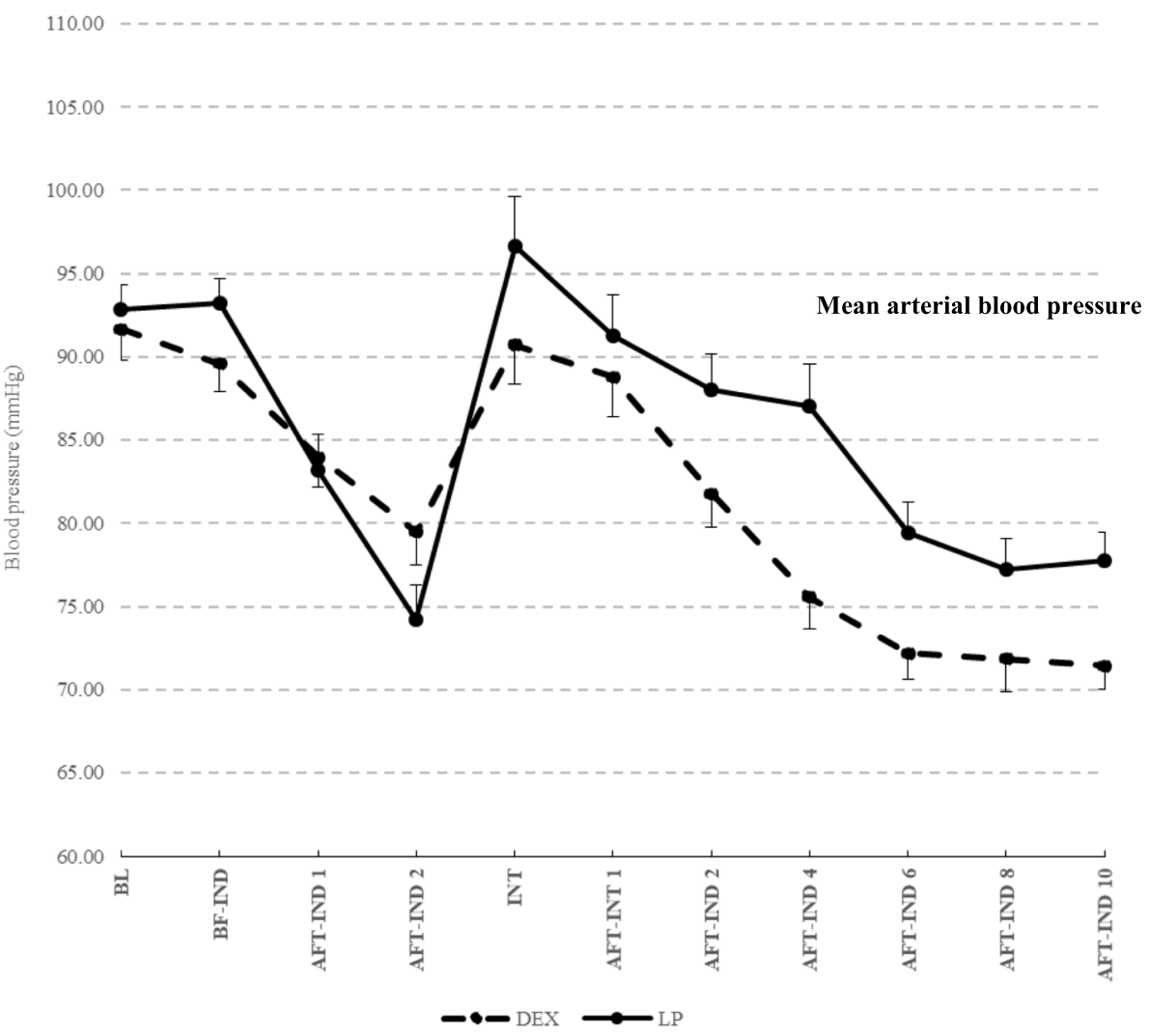

Fig. 4 Mean of Mean arterial Blood Pressure for each time point (Dash line, DEX; Solid line, LP)

that intravenous sedation with dexmedetomidine alone resulted in safety and a few adverse events in awake fiberoptic intubation. Each of the techniques for intubation would stimulate the different hemodynamic responses. It can be seen that the administration of anesthesia should be adjusted according to the intensity of the stimulus so it can lead to a reduction in complications. Wilson and colleagues demonstrated that lidocaine alone can reduce BP but not the chronotropic response to laryngoscopy and tracheal intubation [11]. Propofol has myocardial-depressant effects and decreases systemic vascular resistance in a dose-dependent manner. Kwon and colleagues [12] found that an additional dose of propofol $\left(0.5 \mathrm{mg} \mathrm{kg}^{-1}\right)$ before intubation could improve intubation conditions significantly. In our study, lidocaine $\left(1.5 \mathrm{mg} \mathrm{kg}^{-1}\right.$, i.v. $)$ given before induction combined with an additional dose of propofol $\left(0.5 \mathrm{mg} \mathrm{kg}^{-1}\right)$ given $30 \mathrm{~s}$ before intubation led to all parameters having similar trends to those elicited using dexmedetomidine. SBP, DBP, and MAP in group LP decreased markedly after induction, and decreased after intubation. Furthermore, we showed that SBP at $2 \mathrm{~min}$ after induction decreased $>20 \%$ from that recorded at baseline. Hendrickx and colleagues [15] and Woods and collaborators [16] reported that propofol and lidocaine (i.v.) had a synergistic effect that led to a significant drop in BP after induction: we postulate that hypotension was due to this synergistic effect. However, there was no significant change in SBP, DBP, or MAP in the intubation phase when compared with that at baseline. Furthermore, the HR in group LP decreased slightly after induction but increased in an acceptable range upon and after intubation.

Dexmedetomidine use has been reported to increase the risk of bradycardia and hypotension $[8,9]$. The prevalence of hypotension and bradycardia in group D was 52.83 and $18.87 \%$, respectively. Yildiz and coworkers [9] used atropine $(0.5 \mathrm{mg}$, i.m. $)$ as premedication $30 \mathrm{~min}$ before infusion of dexmedetomidine $\left(1.0 \mu \mathrm{g} \mathrm{kg}^{-1}\right)$ for tracheal intubation, and the prevalence of hypotension (16\%) and bradycardia (4\%) was lower than that in our study. However, a study using lidocaine with an additional low dose of propofol before induction to blunt the cardiovascular reflex has not been caried out. The prevalence of hypotension and bradycardia in group LP was 15.09 and $0 \%$, respectively, which were lower than those in group D and statistically significant. Our study had some limitations. First, our study included only healthy, non-obese, and young patients of ASA physical status 


\section{Systolic blood pressure $(90 \%$ confidence interval)}

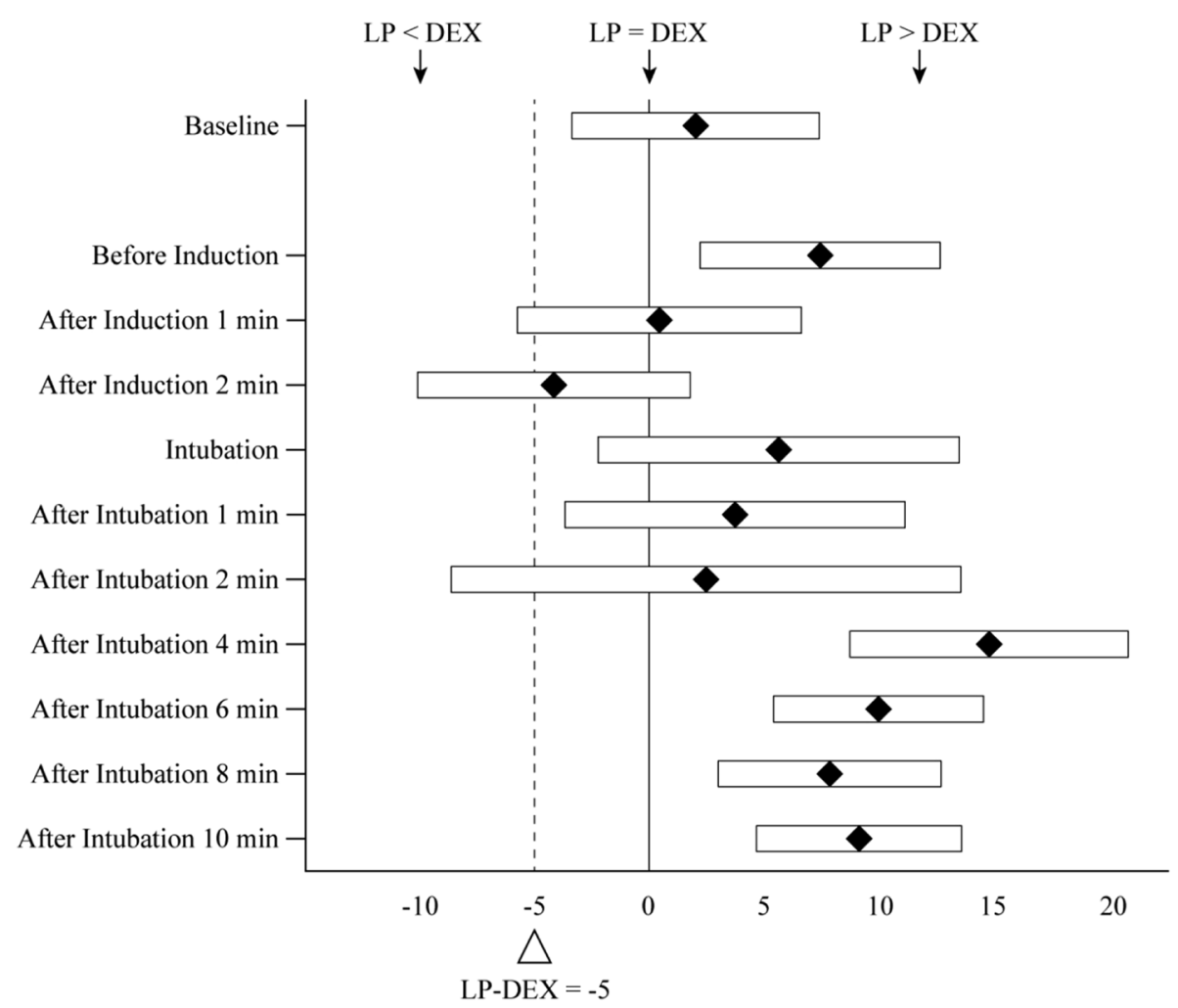

Fig. 5 Forest plot showing the superiority and non-inferiority hypothesis testing for all-time systolic blood pressure differences between groups

I-II. Second, we did not measure the depth of anesthesia during the procedure in either group owing to a lack of facilities. An inadequate depth of anesthesia can lead to an increase in the hemodynamic response to intubation. Third, our study cohort was healthy, so we did not use invasive monitoring. The latter might be more sensitive and provide a more accurate measurement of hemodynamic change, including intravascular postoperative blood glucose was not analyzed Finally, anesthesiologists were not blinded to the group of study subjects. However, they would follow to the study protocol.

Further study should include obese cases patients with ASA physical status $>$ II or history of atrial fibrillation or other arrhythmias, implanted pacemakers, used of the antiarrhythmic drugs or beta blockers. In addition, a study in cost-effectiveness should be conducted.

Our data suggest that lidocaine with propofol could be used as an alternative to a direct sympathomimetic response from laryngoscopy and laryngeal intubation. Moreover, administration of lidocaine and propofol is less expensive than dexmedetomidine administration and associated with fewer complications.

\section{Conclusions}

Lidocaine $\left(1.5 \mathrm{mg} \mathrm{kg}^{-1}\right)$ with additional propofol $\left(0.5 \mathrm{mg} \mathrm{kg}^{-1}\right)$ had a non-inferior effect compared with that of dexmedetomidine $\left(1 \mu \mathrm{g} \mathrm{kg}^{-1}\right)$ for attenuating the hemodynamic response following laryngoscopy and endotracheal intubation only in healthy patients, and was also associated with fewer complications.

\section{Abbreviations}

BP: Blood pressure; HR: Heart rate; SBP: Systolic blood pressure; DBP: Diastolic blood pressure; MAP: Mean arterial pressure; ASA: American Society of

Anesthesiologists.

\section{Acknowledgements}

We thank Assistant Professor Dr. Chomchaba Sirinan (Research Associates, Department of Anesthesiology, Ramathibodi Hospital, Mahidol University) for supporting this study. We thank Arshad Makhdum, PhD, from Edanz Group (https://en-author-services.edanz.com/ac) for editing a draft of this manuscript.

\section{Authors' contributions}

RS and KP were involved in the design of this study, data collection, analysis and interpretation of data, drafting, revising the manuscript of the article and final approval of the version to be published. SI, SK and RK assisted in data collection, analysis and interpretation of data. All authors had read and approved the final manuscript. 


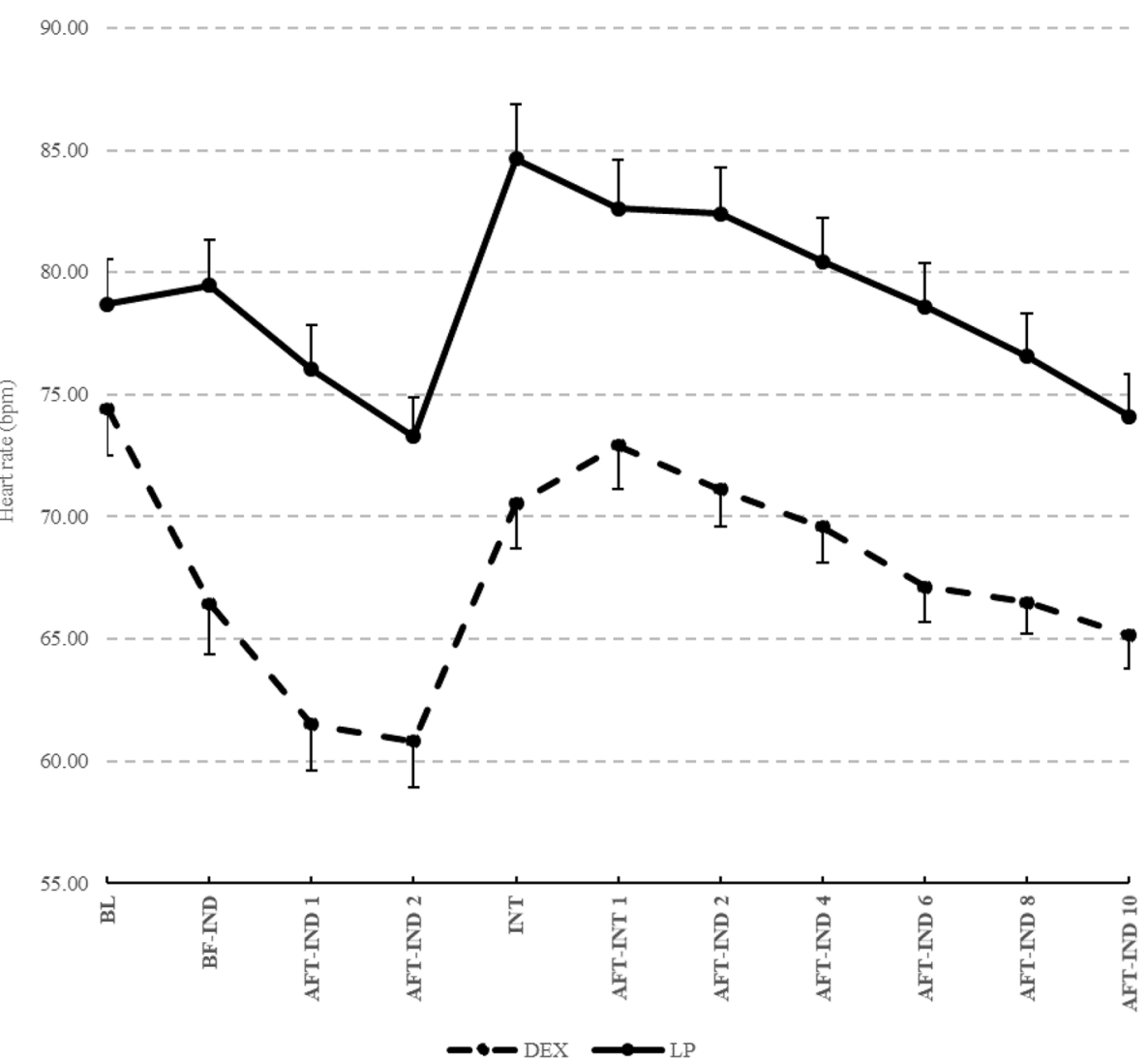

Fig. 6 Mean of Heart rate for each time point (Dash line, DEX; Solid line, LP)

\section{Funding}

This work was supported by grants from the Faculty of Medicine, Ramathibodi Hospital, Mahidol University. The funders had no role in study design, data collection/analyses, decision to publish, or manuscript preparation.

\section{Availability of data and materials}

The trial protocol, datasets used and/or analysed of this study are available from the corresponding author on reasonable request.

\section{Declarations}

\section{Ethics approval and consent to participate}

After approval by the Ethics Committee (Chairman: Assistant Professor Dr. Chusak Okascharoen) of the Faculty of Medicine of Ramathibodi Hospital (Mahidol University, Bangkok, Thailand). This trial is registered at Thai Clinical Trial Registry on the 4 February 2019 (http://www.clinicaltrials.in. th/TRTC20190206002) and adhered to the CONSORT statement. We herein confirm written consent obtained from each patient in accordance with the

Table 3 Adverse effects or complications

\begin{tabular}{lllr}
\hline Adverse effects or complications & Group & \multicolumn{2}{c}{ P value } \\
\cline { 2 - 3 } & D ( $\boldsymbol{n = 5 3 )}$ & LP ( $\boldsymbol{n = 5 3 )}$ & \\
\hline Bradycardia (Number [\%]) & $10[18.87]$ & $0[0.00]$ & $0.001^{*}$ \\
Hypotension (Number [\%]) & $28[52.83]$ & $8[15.09]$ & $<0.001^{*}$
\end{tabular}

Declaration of Helsinki in order to report and publish the individual patient data obtained. All patients provided written informed consent to participate in the trial, according to the national regulations.

\section{Consent for publication}

Not Applicable.

\section{Competing interests}

The authors declare no conflict of interest.

Received: 5 February 2021 Accepted: 23 September 2021

Published online: 30 October 2021

\section{References}

1. Shribman AJ, Smith G, Achola KJ. Cardiovascular and catecholamine responses to laryngoscopy with and without tracheal intubation. $\mathrm{Br} J$ Anaesth. 1987:59(3):295-9.

2. Derbyshire DR, Chmielewski A, Fell D, Vater M, Achola K, Smith G. Plasma catecholamine responses to tracheal intubation. Br J Anaesth. 1983;55:855-60.

3. King BD, Harris LC, Greifenstein FE, Elder JD, Dripps RD. Reflex circulatory responses to direct laryngoscopy and tracheal intubation performed during general anesthesia. Anesthesiology. 1951;12(5):556-66.

4. Fox EJ, Sklar GS, Hill CH, Villanueva R, King BD. Complications related to the pressor response to endotracheal intubation. Anesthesiology. 1977:47(6):524-5.

${ }^{*} P<0.05$ 
5. Gunalan S, Venkatraman R, Sivarajan G, Sunder P. Comparative evaluation of bolus administration of dexmedetomidine and fentanyl for stress attenuation during laryngoscopy and endotracheal intubation. J Clin Diagn Res. 2015;9(9):Uc06-9.

6. Gulabani M, Gurha P, Dass P, Kulshreshtha N. Comparative analysis of efficacy of lignocaine $1.5 \mathrm{mg} / \mathrm{kg}$ and two different doses of dexmedetomidine $(0.5 \mathrm{mug} / \mathrm{kg}$ and $1 \mathrm{mug} / \mathrm{kg})$ in attenuating the hemodynamic pressure response to laryngoscopy and intubation. Anesth Essays Res. 2015;9(1):5-14.

7. Kunisawa T, Nagata O, Nagashima M, et al. Dexmedetomidine suppresses the decrease in blood pressure during anesthetic induction and blunts the cardiovascular response to tracheal intubation. J Clin Anesth. 2009:21:194-9.

8. Reddy SV, Balaji D, Ahmed SN. Dexmedetomidine versus esmolol to attenuate the hemodynamic response to laryngoscopy and tracheal intubation: a randomized double-blind clinical study. Int J Appl Basic Med Res. 2014;4(2):95-100.

9. Yildiz M, Tavlan A, Tuncer S, Reisli R, Yosunkaya A, Otelcioglu S. Effect of dexmedetomidine on haemodynamic responses to laryngoscopy and intubation: perioperative haemodynamics and anaesthetic requirements. Drugs R\&D. 2006;7(1):43-52.

10. Tam S, Chung F, Campbell M. Intravenous lidocaine: optimal time of injection before tracheal intubation. Anesth Analg. 1987;66(10):1036-8.

11. Wilson IG, Meiklejohn BH, Smith G. Intravenous lignocaine and sympathoadrenal responses to laryngoscopy and intubation. Anaesthesia. 1991;46:177-80
12. Kwon MA, Kim SK, Jeon DG, Song JK, Kim WI. The effect of additional propofol on intubation conditions. J Clin Anesth. 2010;22(8):603-7.

13. Dashti M, Amini S, Azarfarin R, Totonchi Z, Hatami M. Hemodynamic changes following endotracheal intubation with glidescope ${ }^{\circledR}$ videolaryngoscope in patients with untreated hypertension. Res Cardiovasc Med. 2014;3:e17598.

14. Cabrini L, Baiardo Redaelli M, Ball L, Filippini M, Fominskiy E, Pintaudi M, et al. Awake fiberoptic intubation protocols in the operating room for anticipated difficult airway: a systematic review and meta-analysis of randomized controlled trials. Anesth Analg. 2019;128(5):971-80. https:// doi.org/10.1213/ANE.0000000000004087.

15. Hendrickx JF, Eger El, Sonner JM, Shafer SL. Is synergy the rule? A review of anesthetic interactions producing hypnosis and immobility. Anesth Analg. 2008;107(2):494-506

16. Woods AW, Grant S, Harten J, Noble JS, Davidson JA. Tracheal intubating conditions after induction with propofol, remifentanil and lignocaine. Eur J Anaesthesiol. 1998;15(6):714-8.

\section{Publisher's Note}

Springer Nature remains neutral with regard to jurisdictional claims in published maps and institutional affiliations.
Ready to submit your research? Choose BMC and benefit from:

- fast, convenient online submission

- thorough peer review by experienced researchers in your field

- rapid publication on acceptance

- support for research data, including large and complex data types

- gold Open Access which fosters wider collaboration and increased citations

- maximum visibility for your research: over 100M website views per year

At BMC, research is always in progress.

Learn more biomedcentral.com/submissions 